\title{
Breast carcinoma with 21-gene recurrence score lower than 18: rate of locoregional recurrence in a large series with clinical follow-up
}

Gulisa Turashvili, ${ }^{1}$ Edi Brogi ${ }^{1}$, Monica Morrow ${ }^{2}$, Maura Dickler ${ }^{3}$, Larry Norton ${ }^{3}$, Clifford Hudis ${ }^{3}$ and Hannah Y. Wen ${ }^{1 *}$ (D)

\begin{abstract}
Background: The 21-gene recurrence score (RS) assay determines the benefit of adding chemotherapy to endocrine therapy for patients with early stage, estrogen receptor (ER)-positive, HER2-negative breast cancer. The RS risk groups predict the likelihood of distant recurrence and have recently been associated with an increased risk of locoregional recurrence (LRR). This study analyzed clinicopathologic features of patients with low RS and LRR.

Methods: In our institutional database, we identified 1396 consecutive female patients with lymph node negative, ER +/HER2- invasive breast carcinoma and low RS (<18) results, treated at our center from 2008 to 2013. We collected data on clinicopathologic features, treatment and outcome.

Results: The median patient age was 57 years (range 22-90). The median tumor size was $1.2 \mathrm{~cm}$ (range 0.3-5.8). Overall, 66.6\% (930/1396) women were treated with breast conserving surgery (BCS) and radiation therapy, 3.4\% (48/ 1396) with BCS alone, 29.7\% (414/1396) with total mastectomy, and 0.3\% (4/1396) with total mastectomy and radiation therapy. Most patients (84.8\%; 1184/1396) received endocrine therapy alone, 12.1\% (169/1396) were treated with chemotherapy plus endocrine therapy, and only 3.1\% (43/1396) received no systemic therapy. At a median follow-up of 52 months, $0.9 \%(13 / 1396)$ of patients developed LRR. Sites of LRR included the ipsilateral breast $(n=8)$, chest wall $(n=3)$, axillary node $(n=1)$, and internal mammary node $(n=1)$. All patients with LRR had negative resection margins at the initial surgery. The rate of LRR in patients treated with adjuvant endocrine therapy alone was $0.7 \%$ (8/1184). All eight patients received standard local treatment. Three patients had lymphovascular invasion but no other significant risk factors for LRR were identified.

Conclusions: Our study of node negative, ER+/HER2- breast cancer patients with low RS observed extremely low rates of LRR: $0.9 \%(13 / 1396)$ in the whole cohort and $0.7 \%$ (8/1184) in patients treated with endocrine therapy alone. As the largest series to date, we report detailed clinicopathologic data and clinical outcomes of this cohort and provide a comprehensive characterization of patients who developed LRR.
\end{abstract}

Keywords: Breast cancer, Estrogen receptor positive, Early stage, 21-gene recurrence score assay, Low risk, Locoregional recurrence

\footnotetext{
* Correspondence: weny@mskcc.org

${ }^{1}$ Department of Pathology, Memorial Sloan Kettering Cancer Center, 1275

York Avenue, New York, NY 10065, USA

Full list of author information is available at the end of the article
} 


\section{Background}

Multigene prognostic gene signatures developed in the last two decades have become an integral part of standard clinical management of breast cancer as they allow to identify patients at a higher risk of distant recurrence [1-5]. The 21-gene recurrence score (RS) assay (Oncotype Dx ${ }^{\mathrm{Tm}}$, Genomic Health, Redwood City, CA) is the most used prognostic assay in the United States, recommended by National Comprehensive Cancer Network and the American Society of Clinical Oncology for patients with early stage, estrogen receptor (ER)-positive, HER2-negative breast cancer [6].

The RS assay utilizes reverse transcriptase polymerase chain reaction (RT-PCR) to quantify the expression of 16 cancer related genes normalized to the expression of five reference genes [3]. The resulting RS is a continuous variable on a scale of 0 to 100 which estimates the five year risk of distant recurrence in patients treated with tamoxifen and the benefit of adding chemotherapy to endocrine therapy $[3,4,7]$. Based on the RS values, breast cancer patients are stratified into three risk cat-

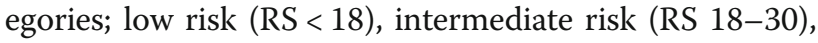
and high risk $(\mathrm{RS}>30)$ [3]. In patients with $\mathrm{RS}<18$, the benefit of chemotherapy is believed to be too small (2\%) to outweigh the risks of secondary side effects. The clinical management of patients with a RS of 18 to 30 varies and includes endocrine therapy with or without chemotherapy depending on other clinicopathologic variables and patient's choice. In contrast, patients with RS $>30$ greatly benefit from chemotherapy due to a significantly increased risk (28\%) of distant metastases reported by many studies [8-17]. The RS risk groups have recently been associated with an increased likelihood of locoregional recurrence (LRR) in several studies [18-20], including a large patient cohort from our institution [21], but the data remain limited.

As the largest series to date, we report detailed clinicopathologic data and clinical outcomes of consecutive female patients with lymph node negative, ER+/HER2breast cancer and low RS $(<18)$ treated at our institution and provide a comprehensive characterization of patients who developed LRR.

\section{Methods}

\section{Study subjects}

At our institution, all lymph node negative, ER+/HER2- invasive breast carcinomas measuring $\geq 0.5 \mathrm{~cm}$ are routinely evaluated with the 21-gene RS assay. In rare cases, testing of selected $<0.5 \mathrm{~cm}$ tumors has also been requested by the clinician if patients are deemed medically suitable for chemotherapy and interested in receiving such treatment. We identified consecutive female patients with early stage, ER+/HER2- invasive breast carcinoma and low RS $(<18)$ treated at our center between September 2008 and August
2013. Our study cohort consists of patients with negative lymph nodes (pNO(i+) and pN0) [22]. Male patients and tumors that failed testing for various technical reasons were excluded from the study.

We recorded clinicopathologic variables for all patients such as age at breast cancer diagnosis, tumor type and size, lymphovascular invasion (LVI), RS result, surgical and medical treatment, and clinical outcome. For multifocal ipsilateral invasive carcinomas, we recorded the size of the largest tumor and the highest RS result. For one patient with metachronous bilateral ER+/HER2breast carcinomas with low RS, we only included data pertaining to the first tumor. We reviewed the institutional database and electronic medical records to identify patients with LRR and recorded sites of recurrence. The Institutional Review Board approved the study.

LRR was defined as the development of invasive breast cancer in the ipsilateral breast parenchyma, axilla, regional lymph nodes, chest wall or skin $\geq 6$ months after the initial diagnosis [23]. The cut-off date for follow-up was September 1st, 2016. All data presented in this article are descriptive. No formal statistical analysis was performed due to the small number of LRR events.

\section{Results}

\section{Patient cohort}

We identified 1396 consecutive female patients with lymph node negative, ER+/HER2- breast cancers and low RS treated at our center during the study period (Table 1). The patient median age at breast cancer diagnosis was 57 years (range 22-90). Most patients (71.8\%: 1002/1396) were $>50$ years old, $23.7 \%(331 / 1396)$ were between 40 and 49 years old, and $4.5 \%(63 / 1396)$ were $<40$ years old at the initial diagnosis of breast cancer. Of the 1396 tumors, $36.2 \%(505 / 1396)$ had a RS of 0 to 10 , and $63.8 \%$ (891/ 1396) had a RS of 11-17. The median tumor size was $1.2 \mathrm{~cm}$ (range 0.3-5.8), and 21.3\% (297/1396) were multifocal. Most tumors $(77.1 \% ; 1076 / 1396)$ were invasive ductal carcinoma (IDC) not otherwise specified, 13.5\% (188/1396) were invasive lobular carcinoma (ILC), 5.2\% (72/1396) were mixed ductal and lobular histology, and 4.3\% (60/1396) were special histologic subtypes. LVI was identified in $19.1 \%(266 / 1396)$ of patients. All patients had a sentinel lymph node biopsy with negative nodes, including $74 \mathrm{pa}-$ tients with isolated tumor cells (ITCs), i.e. pNO(i+).

Overall, 66.6\% (930/1396) women were treated with breast conserving surgery (BCS) and radiation therapy, $3.4 \%$ (48/1396) with BCS alone, 29.7\% (414/1396) with total mastectomy, and $0.3 \%(4 / 1396)$ with total mastectomy and radiation therapy. Most (96.9\%; 1353/1396) patients received endocrine therapy, including 84.8\% (1184/1396) treated with endocrine therapy alone and 12.1\% (169/1396) treated with chemotherapy plus endocrine therapy. Only $3.1 \%(43 / 1396)$ received no systemic therapy. 
Table 1 Clinicopathologic characteristics of all 1396 patients with lymph node negative ER+/HER2- breast cancer and RS < 18 (all percentages within columns)

\begin{tabular}{|c|c|c|c|}
\hline & RS 0-10 $(n=505)$ & RS $11-17(n=891)$ & Total $(n=1396)$ \\
\hline RS: mean, median (range) & $7,8(0-10)$ & $14,14(11-17)$ & $12,12(0-17)$ \\
\hline \multicolumn{4}{|l|}{ Age at diagnosis } \\
\hline Mean, median (range); years & $58,59(25-84)$ & $56,55(22-90)$ & $57,57(22-90)$ \\
\hline$<40$ years; $\mathrm{n}(\%)$ & $21(4.2 \%)$ & $42(4.7 \%)$ & $63(4.5 \%)$ \\
\hline 40-49 years; $n(\%)$ & $111(22 \%)$ & $220(24.7 \%)$ & $331(23.7 \%)$ \\
\hline$\geq 50$ years; $n(\%)$ & $373(73.9 \%)$ & $629(70.6 \%)$ & $1002(71.8 \%)$ \\
\hline Tumor size: mean, median (range); cm & $1.31,1.2(0.4-5.8)$ & $1.32,1.2(0.3-4.7)$ & $1.32,1.2(0.3-5.8)$ \\
\hline Multifocality; n (\%) & $123(24.4 \%)$ & $174(19.5 \%)$ & $297(21.3 \%)$ \\
\hline LVl; n (\%) & $90(19.8 \%)$ & $176(17.8 \%)$ & $266(19.1 \%)$ \\
\hline \multicolumn{4}{|l|}{ Local treatment; n (\%) } \\
\hline BCS only & $15(3 \%)$ & $33(3.7 \%)$ & $48(3.4 \%)$ \\
\hline $\mathrm{BCS}$ and radiation therapy & $319(63.2 \%)$ & $611(68.6 \%)$ & $930(66.6 \%)$ \\
\hline Total mastectomy & $171(33.9 \%)$ & $243(27.3 \%)$ & $414(29.7 \%)$ \\
\hline Total mastectomy and radiation therapy & 0 & $4(0.4 \%)^{b}$ & $4(0.3 \%)^{b}$ \\
\hline \multicolumn{4}{|l|}{ Systemic therapy; n (\%) } \\
\hline Endocrine therapy alone & $462(91.5 \%)$ & 722 (81\%) & $1184(84.8 \%)$ \\
\hline Endocrine therapy and chemotherapy ${ }^{a}$ & $22(4.4 \%)$ & $147(16.5 \%)^{\mathrm{a}}$ & $169(12.1 \%)^{a}$ \\
\hline No systemic therapy & $21(4.2 \%)$ & $22(2.5 \%)$ & $43(3.1 \%)$ \\
\hline Median follow-up (range); months & $52(0.9-108.3)$ & $52.2(1-93)$ & $52(0.9-108.3)$ \\
\hline LRR; n (\%) & $5(1 \%)$ & $8(0.9 \%)$ & $13(0.9 \%)$ \\
\hline
\end{tabular}

$B C S$ breast conserving surgery, $L R R$ locoregional recurrence, $L V I$ lymphovascular invasion, $R S$ recurrence score.

${ }^{a}$ One patient did not complete endocrine therapy

${ }^{\mathrm{b}}$ Radiation therapy following total mastectomy was given for ductal carcinoma in situ within $1 \mathrm{~mm}$ of the surgical margin $(n=3)$, and large $(7 \mathrm{~cm})$ tumor $(n=1)$

Eight of 1396 (0.6\%) patients developed distant metastases. None of these eight patients had LRR. One patient $(0.1 \%)$ with distant metastases died of disease 64 months after her initial breast cancer diagnosis, six patients $(0.4 \%)$ died of other causes, and six patients $(0.4 \%)$ died of unknown causes.

\section{Patients with locoregional recurrence (LRR)}

We recently demonstrated that RS is significantly associated with the risk of LRR in a large cohort of lymph node negative, ER+/HER2- breast cancer patients [21]. The risk of LRR was increased >4-fold (hazard ratio: $4.61,95 \% \mathrm{CI}$ 1.90-11.19, $p<0.01$ ) and 3-fold (hazard ratio: 2.81, 95\% CI 1.41-5.56, $\mathrm{p}<0.01)$ for high and intermediate risk groups compared to the low risk group [21].

At a median follow-up of 52 months (range 0.9$108.3), 0.9 \%(13 / 1396)$ of patients with low RS developed LRR. The LRR occurred within five years of the index breast cancer diagnosis in 11 patients (Table 2). LRR was confirmed by pathologic examination of a biopsy specimen of the recurrent tumor tissue in all 13 patients. Sites of LRR included the ipsilateral breast $(n=8)$, chest wall $(n=3)$, axillary node $(n=1)$, and internal mammary node $(n=1)$. The index tumors of all 13 patients with
LRR had been excised with negative margins (no ink on carcinoma). All patients were pNO, and none was pNO(i $+)$. Of the 13 patients, four had a total mastectomy, seven had BCS with radiation therapy, and two (both $>70$ years old) had BCS alone. Eight patients were treated with endocrine therapy alone, four patients received combined endocrine therapy and chemotherapy, and one patient received no systemic therapy.

Of the 13 patients with LRR, five patients (38.5\%) had a RS of 0 to 10 , while eight patients (61.5\%) were in the RS 11-17 group. None of the 13 patients with LRR was enrolled in the TAILORx or RxPONDER trials (see Discussion).

\section{Patients treated with adjuvant endocrine therapy only}

Of the 1396 patients, most patients $(84.8 \%$; 1184/1396) were treated with adjuvant endocrine therapy and no chemotherapy (Table 3$)$. Only $0.7 \%(8 / 1184)$ of patients developed LRR in this treatment group. All eight patients were alive at the last follow-up. Two of the eight patients with LRR were $<40$ years old at the initial diagnosis of breast cancer. All patients were pN0, and none was $\mathrm{pNO}(\mathrm{i}+)$. Five patients had a family history of breast cancer, but none of the four patients who underwent 
Table 2 Clinicopathologic characteristics of all 1396 patients of lymph node negative ER+/HER2- breast cancer with $\mathrm{RS}<18$ by LRR (all percentages within columns)

\begin{tabular}{|c|c|c|}
\hline & $\begin{array}{l}\text { No LRR } \\
(n=1383)\end{array}$ & $\begin{array}{l}\operatorname{LRR} \\
(n=13)\end{array}$ \\
\hline \multicolumn{3}{|l|}{ RS } \\
\hline Mean, median (range) & $12,12(0-17)$ & $11,12(0-17)$ \\
\hline RS 0-10; n (\%) & $500(36.2 \%)$ & $5(38.5 \%)$ \\
\hline RS 11-17; n (\%) & $883(63.8 \%)$ & $8(61.5 \%)$ \\
\hline \multicolumn{3}{|l|}{ Age at diagnosis } \\
\hline Mean, median (range); years & $57,57(22-90)$ & $55,54(35-79)$ \\
\hline$<40$ years; $n(\%)$ & $61(4.4 \%)$ & $2(15.4 \%)$ \\
\hline 40-49 years; $n(\%)$ & $328(23.7 \%)$ & $3(23.1 \%)$ \\
\hline$\geq 50$ years; $\mathrm{n}(\%)$ & $994(71.9 \%)$ & $8(61.5 \%)$ \\
\hline Tumor size, median (range); cm & $1.31,1.2(0.3-5.8)$ & $1.5,1.3(0.5-3.5)$ \\
\hline Multifocality; n (\%) & $291(21 \%)$ & $6(46.2 \%)$ \\
\hline LVl; n (\%) & $262(18.9 \%)$ & $4(30.8 \%)$ \\
\hline \multicolumn{3}{|l|}{ Local treatment; n (\%) } \\
\hline BCS only & $46(3.3 \%)$ & $2(15.4 \%)$ \\
\hline $\mathrm{BCS}$ and radiation therapy & $923(66.7 \%)$ & 7 (53.8\%) \\
\hline Total mastectomy & $410(29.6 \%)$ & $4(30.8 \%)$ \\
\hline $\begin{array}{l}\text { Total mastectomy and radiation } \\
\text { therapy }{ }^{\mathrm{b}}\end{array}$ & $4(0.3 \%)^{b}$ & 0 \\
\hline \multicolumn{3}{|l|}{ Systemic therapy; n (\%) } \\
\hline Endocrine therapy only & $1176(85 \%)$ & $8(61.5 \%)$ \\
\hline $\begin{array}{l}\text { Endocrine therapy and } \\
\text { chemotherapy }{ }^{\mathrm{a}}\end{array}$ & $165(11.9 \%)^{a}$ & $4(30.8 \%)$ \\
\hline No systemic therapy & $42(3 \%)$ & $1(7.7 \%)$ \\
\hline Median follow-up (range); months & $51.9(0.9-108.3)$ & $71.4(43.2-86.8)$ \\
\hline $\begin{array}{l}\text { Time to LRR, median (range), } \\
\text { months }\end{array}$ & - & $36.5(9.7-74.3)$ \\
\hline
\end{tabular}

$B C S$ breast conserving surgery, $L R R$ locoregional recurrence, $L V I$ lymphovascular invasion, $R S$ recurrence score ${ }^{a}$ One patient did not complete endocrine therapy

${ }^{b}$ Radiation therapy following total mastectomy was given for ductal carcinoma in situ within $1 \mathrm{~mm}$ of the surgical margin $(n=3)$, and large $(7 \mathrm{~cm})$ tumor $(n=1)$

genetic testing had germline BRCA1 or BRCA2 gene mutations (Table 4). All eight patients received standard local treatment. Three patients had LVI but no other significant risk factors for LRR were identified.

\section{Discussion}

As demonstrated by retrospective analysis of randomized clinical trials and non-randomized studies, the 21-gene RS assay is invaluable in guiding treatment recommendations for patients with early stage, ER+/HER2- breast cancer [817, 24]. Data from the NSABP (the National Surgical Adjuvant Breast and Bowel Project) B14 and B20 patients with node negative, ER+/HER2- breast cancer suggest that besides quantifying the likelihood of distant recurrence (prognostic value) within ten years of the initial diagnosis [3], the RS assay estimates the magnitude of chemotherapy benefit (predictive value) [4]. Recently, the RS risk categories have been reported to be associated with an increased risk of LRR [18-21]. Little is known about a subset of patients that develop LRR, especially in the low RS group. We recently documented a very low distant recurrence rate in node negative, ER+/HER2- breast cancer patients with low RS treated at our institution [25]. In this study, we report the rate of LRR and clinicopathologic characteristics of women with LRR in the same patient cohort.

Our study shows that $>99 \%$ of women were free of LRR at a median follow up of 52 months. Only 0.9\% (13/1396) developed LRR in this cohort of consecutive female patients. None of the 13 patients with LRR had distant metastases. Other studies reported similar low rates of LRR and breast cancer specific mortality in patients with low RS. A study of 163 patients showed that a RS $>24$ was associated with LRR in patients treated with total mastectomy but not in those treated with BCS. Among women treated with total mastectomy, the five year LRR rate was $27.3 \%$ in patients with a RS $>24$ versus $10.7 \%$ in patients with a RS $\leq$ 24 [19]. In another study, RS was a predictor of LRR along with age and treatment type in multivariate analysis [18]. Mamounas et al. reported a ten year LRR of 4.3\% (95\% CI, $2.3 \%$ to $6.3 \%$ ) in tamoxifen treated patients with a low RS, and significant associations between RS and LRR in tamoxifen treated patients from NSABP B14 and B20 trials $(p<$ $0.001)$, placebo treated patients from NSABP B14 trial $(P=$ 0.022 ), and in chemotherapy plus tamoxifen treated patients from NSABP B20 trial $(P=0.028)[18]$.

An increased risk of LRR has been linked to a variety of clinicopathologic factors including patient age, tumor size and grade, LVI, the number of positive lymph nodes, bilateral breast cancer, ER/PR status, Ki67 proliferation index and the length of endocrine therapy [26-30]. Of the eight patients treated with endocrine therapy alone, three women had LVI on excision but no other significant risk factors for LRR were identified. Furthermore, all eight patients received standard local treatment.

The final results of two ongoing prospective studies, TailoRx (Trial Assigning IndividuaLized Options for treatment $(\mathrm{Rx})$ ) and RxPONDER ( $\mathrm{Rx}$ for Positive Node, Endocrine Responsive breast cancer) [31-33] are not yet available. Notably, to minimize the risk of omitting chemotherapy, the TailoRx trial narrowed the low risk group to a RS of 010 , expanded the intermediate risk group to include tumors with a RS of 11-25, and defined the high risk group as a RS $\geq 26$ [31, 32]. Data from TailoRx for patients with RS 010 treated with hormonal therapy alone shows that $98.7 \%$ are free of distant recurrence or LRR at five years after the initial diagnosis of breast cancer [32]. In our cohort, the rate of LRR in the RS 0-10 group treated with only adjuvant endocrine therapy was $0.6 \%(3 / 462)$, consistent with the results of the TailoRx trial. 
Table 3 Clinicopathologic characteristics of 1184 cases of lymph node negative ER+/HER2- breast cancer with RS $<18$, treated with endocrine therapy only (all percentages within columns)

\begin{tabular}{|c|c|c|c|}
\hline & RS $0-10(n=462)$ & RS $11-17(n=722)$ & Total $(n=1184)$ \\
\hline RS: Mean, median (range) & $7,8(0-10)$ & $14,14(11-17)$ & $11,12(0-17)$ \\
\hline \multicolumn{4}{|l|}{ Age at diagnosis } \\
\hline Mean, median (range); years & $58,59(25-84)$ & $58,57(22-90)$ & $58,58(22-90)$ \\
\hline$<40$ years; $\mathrm{n}(\%)$ & $19(4.1 \%)$ & $21(2.9 \%)$ & $40(3.4 \%)$ \\
\hline 40-49 years; $n(\%)$ & $98(21.2 \%)$ & $156(21.6 \%)$ & $254(21.5 \%)$ \\
\hline$\geq 50$ years; $\mathrm{n}(\%)$ & $345(74.7 \%)$ & $545(75.5 \%)$ & $890(75.2 \%)$ \\
\hline Tumor size, median (range); $\mathrm{cm}$ & $1.28,1.1(0.35-5.5)$ & $1.28,1.1(0.3-4.5)$ & $1.28,1.1(0.3-5.5)$ \\
\hline Multifocality; n (\%) & $106(22.9 \%)$ & $128(17.7 \%)$ & $234(19.8 \%)$ \\
\hline LVl; n (\%) & $72(15.6 \%)$ & $126(17.5 \%)$ & $198(16.7 \%)$ \\
\hline \multicolumn{4}{|l|}{ Local treatment; n (\%) } \\
\hline BCS only & $12(2.6 \%)$ & $28(3.9 \%)$ & $40(3.4 \%)$ \\
\hline BCS and radiation therapy & $301(65.2 \%)$ & $515(71.3 \%)$ & $816(68.9 \%)$ \\
\hline Total mastectomy & $149(32.3 \%)$ & $177(24.5 \%)$ & $326(27.5 \%)$ \\
\hline Total mastectomy and radiation therapy & 0 & $2(0.3 \%)$ & $2(0.2 \%)$ \\
\hline LRR; n (\%) & $3(0.6 \%)$ & $5(0.7 \%)$ & $8(0.7 \%)$ \\
\hline Median follow-up (range); months & $51.7(0.9-108.3)$ & $51.3(1-93)$ & $51.4(0.9-108.3)$ \\
\hline
\end{tabular}

$B C S$ breast conserving surgery, $L R R$ locoregional recurrence, $L V I$ lymphovascular invasion, $R S$ recurrence score

Table 4 Clinicopathologic characteristics of eight patients with LRR in the patient cohort treated with endocrine therapy and no chemotherapy

\begin{tabular}{|c|c|c|c|c|c|c|c|c|}
\hline Patients & $\# 1$ & $\# 2$ & \#3 & $\# 4$ & $\# 5$ & $\# 6$ & \#7 & \#8 \\
\hline $\begin{array}{l}\text { Family history of breast } \\
\text { cancer }\end{array}$ & No & Yes & Yes & Yes & Yes & Yes & No & No \\
\hline BRCA mutations & Negative & Negative & Negative & Negative & Negative & Not tested & Not tested & Not tested \\
\hline Tumor histotype & $\begin{array}{l}\text { IDC, Grade } \\
2\end{array}$ & IDC, Grade 2 & $\begin{array}{l}\text { IDC, Grade } \\
1\end{array}$ & IDC, Grade 2 & $\begin{array}{l}\text { ILC, not } \\
\text { graded }\end{array}$ & IDC, Grade 1 & IDC, Grade 2 & IDC, Grade 2 \\
\hline Tumor size $(\mathrm{cm})$ & 0.7 & 2.2 & 1.5 & 0.7 & 2.1 & 1.3 & 2 & 3.5 \\
\hline Multifocality & Yes & Yes & Yes & No & No & No & No & No \\
\hline LVI & No & No & No & Yes & No & No & Yes & Yes \\
\hline ER IHC (\%) & 100 & 80 & 90 & 98 & 98 & 100 & 95 & 98 \\
\hline PR IHC (\%) & 100 & 70 & 90 & 20 & 10 & 70 & 40 & 98 \\
\hline RS & 0 & 14 & 7 & 16 & 14 & 4 & 17 & 12 \\
\hline ESR1 expression & 11.2 & 10.4 & 9.8 & 9.8 & 10.2 & 12.1 & 11.5 & 11.8 \\
\hline PgR expression & $>10$ & 8.8 & 8.7 & 5.8 & 6.6 & 9.1 & 6.3 & $>10$ \\
\hline Surgery & TM & TM & TM & $\mathrm{BCS}$ & $\mathrm{BCS}$ & $\mathrm{BCS}$ & $\mathrm{BCS}$ & $\mathrm{BCS}$ \\
\hline Radiation therapy & No & No & No & Yes & Yes & No & Yes & No \\
\hline Time to LRR (months) & 42 & 65 & 29 & 50 & 37 & 41 & 24 & 46 \\
\hline Site of LRR & Chest wall & $\begin{array}{l}\text { Internal mammary } \\
\text { node }\end{array}$ & Chest wall & $\begin{array}{l}\text { Ipsilateral } \\
\text { breast }\end{array}$ & $\begin{array}{l}\text { Ipsilateral } \\
\text { breast }\end{array}$ & $\begin{array}{l}\text { Ipsilateral } \\
\text { breast }\end{array}$ & $\begin{array}{l}\text { Ipsilateral } \\
\text { breast }\end{array}$ & $\begin{array}{l}\text { Ipsilateral } \\
\text { breast }\end{array}$ \\
\hline
\end{tabular}


Our study cohort is unique as it consists of a large, consecutive population of women with low RS treated at a single institution with available clinical follow-up information. The 21-gene RS assay results were prospectively included and considered in the treatment planning for all patients. The main limitations of our study include its retrospective design and the low number of LRR events precluding a formal statistical analysis. In addition, our results may be less applicable to general patient populations as our tertiary academic institution predominantly treats women with screen detected breast cancer and women from a specific geographic region. The follow-up interval is less than five years in some patients due to the relatively recent implementation of the 21-gene RS assay. However, compared to our previous publication [25], we now report LRR rates at a longer median follow-up of 52 months.

\section{Conclusions}

Our study of node negative, ER+/HER2- breast cancer patients with low RS $(<18)$ observed extremely low rates of LRR: $0.9 \%(13 / 1396)$ in the whole cohort and $0.7 \%(8 /$ 1184 ) in patients treated with endocrine therapy alone. We report detailed clinicopathologic features of women who developed LRR in this low RS cohort.

\begin{abstract}
Abbreviations
BCS: Breast conserving surgery; ER: Estrogen receptor; IDC: Invasive ductal carcinoma; ILC: Invasive lobular carcinoma; ITC: Isolated tumor cells; LRR: Locoregional recurrence; LVI: Lymphovascular invasion; NSABP: The National Surgical Adjuvant Breast and Bowel Project; RS: Recurrence score; RT-PCR: Reverse transcriptase polymerase chain reaction; RxPONDER: Rx for Positive Node, Endocrine Responsive breast cancer; TailoRx: Trial Assigning IndividuaLized Options for treatment (Rx)
\end{abstract}

\section{Acknowledgements}

We thank Ms. Alicja Wiszowaty, Ms. Angelica Martin and Ms. Katherine Lopez for their invaluable assistance with data collection.

\section{Funding}

Research reported in this publication was supported in part by a Cancer Center Support Grant of the National Institutes of Health/National Cancer Institute (Grant No. P30CA008748). The funding body played no role in the design of the study, collection, analysis and interpretation of data, or in writing the manuscript.

\section{Availability of data and materials}

Datasets used in this study are available from the corresponding author on reasonable request.

\section{Authors' contributions}

GT: Investigation, data curation, writing (original draft); MM, MD, LN and $\mathrm{CH}$ : Writing (review and editing); EB: Conceptualization, methodology, writing (review and editing), supervision; HYW: Conceptualization, methodology, validation, formal analysis, investigation, resources, data curation, visualization, supervision. All authors contributed to the critical revision and editing of the manuscript. All authors read and approved the final manuscript.

\section{Ethics approval and consent to participate}

The study was approved by the Institutional Review Board of Memorial Sloan Kettering Cancer Center, New York, NY, USA. For this type (retrospective) of study formal consent is not required.
Consent for publication

Not applicable.

\section{Competing interests}

The authors declare that they have no competing interests.

\section{Publisher's Note}

Springer Nature remains neutral with regard to jurisdictional claims in published maps and institutional affiliations.

\section{Author details}

${ }^{1}$ Department of Pathology, Memorial Sloan Kettering Cancer Center, 1275 York Avenue, New York, NY 10065, USA. ${ }^{2}$ Department of Surgery, Memorial Sloan Kettering Cancer Center, New York, NY 10065, USA. ${ }^{3}$ Department of Medicine, Memorial Sloan Kettering Cancer Center, New York, NY 10065, USA.

Received: 11 July 2017 Accepted: 27 December 2017

Published online: 06 January 2018

\section{References}

1. van de Vijver MJ, He YD, van't Veer LJ, Dai H, Hart AA, Voskuil DW, Schreiber GJ, Peterse JL, Roberts C, Marton MJ, et al. A gene-expression signature as a predictor of survival in breast cancer. N Engl J Med. 2002;347(25):1999-2009.

2. van 't Veer $L$, Dai $H$, van de Vijver MJ, He YD, Hart AA, Mao M, Peterse HL, van der Kooy K, Marton MJ, Witteveen AT, et al. Gene expression profiling predicts clinical outcome of breast cancer. Nature. 2002;415(6871):530-6.

3. Paik S, Shak S, Tang G, Kim C, Baker J, Cronin M, Baehner FL, Walker MG, Watson D, Park T, et al. A multigene assay to predict recurrence of tamoxifentreated, node-negative breast cancer. N Engl J Med. 2004;351(27):2817-26.

4. Paik S, Tang G, Shak S, Kim C, Baker J, Kim W, Cronin M, Baehner FL, Watson $D$, Bryant J, et al. Gene expression and benefit of chemotherapy in women with node-negative, estrogen receptor-positive breast cancer. J Clin Oncol. 2006;24(23):3726-34

5. Gyorffy B, Hatzis C, Sanft T, Hofstatter E, Aktas B, Pusztai L. Multigene prognostic tests in breast cancer: past, present, future. Breast Cancer Res. 2015;17:11.

6. Harris $L$, Fritsche $H$, Mennel $R$, Norton $L$, Ravdin $P$, Taube $S$, Somerfield MR, Hayes DF, Bast RC Jr, American Society of Clinical O. American Society of Clinical Oncology 2007 update of recommendations for the use of tumor markers in breast cancer. J Clin Oncol. 2007;25(33):5287-312.

7. Albain KS, Barlow WE, Shak S, Hortobagyi GN, Livingston RB, Yeh IT, Ravdin P, Bugarini R, Baehner FL, Davidson NE, et al. Prognostic and predictive value of the 21-gene recurrence score assay in postmenopausal women with nodepositive, oestrogen-receptor-positive breast cancer on chemotherapy: a retrospective analysis of a randomised trial. Lancet Oncol. 2010;11(1):55-65.

8. Lo SS, Mumby PB, Norton J, Rychlik K, Smerage J, Kash J, Chew HK, Gaynor ER, Hayes DF, Epstein A, et al. Prospective multicenter study of the impact of the 21-gene recurrence score assay on medical oncologist and patient adjuvant breast cancer treatment selection. J Clin Oncol. 2010;28(10):1671-6.

9. Ademuyiwa FO, Miller A, O'Connor T, Edge SB, Thorat MA, Sledge GW, Levine $E$, Badve $S$. The effects of oncotype DX recurrence scores on chemotherapy utilization in a multi-institutional breast cancer cohort. Breast Cancer Res Treat. 2011;126(3):797-802.

10. Geffen DB, Abu-Ghanem S, Sion-Vardy N, Braunstein R, Tokar M, Ariad $\mathrm{S}$, Delgado B, Bayme M, Koretz M. The impact of the 21-gene recurrence score assay on decision making about adjuvant chemotherapy in early-stage estrogen-receptor-positive breast cancer in an oncology practice with a unified treatment policy. Ann Oncol. 2011:22(11):2381-6

11. Partin JF, Mamounas EP. Impact of the 21-gene recurrence score assay compared with standard clinicopathologic guidelines in adjuvant therapy selection for node-negative, estrogen receptor-positive breast cancer. Ann Surg Oncol. 2011;18(12):3399-406.

12. Albanell J, Gonzalez A, Ruiz-Borrego M, Alba E, Garcia-Saenz JA, Corominas JM, Burgues O, Furio V, Rojo A, Palacios J, et al. Prospective transGEICAM study of the impact of the 21-gene recurrence score assay and traditional clinicopathological factors on adjuvant clinical decision making in women with estrogen receptor-positive (ER+) node-negative breast cancer. Ann Oncol. 2012;23(3):625-31. 
13. Joh JE, Esposito NN, Kiluk JV, Laronga C, Lee MC, Loftus L, Soliman H, Boughey JC, Reynolds C, Lawton TJ, et al. The effect of Oncotype DX recurrence score on treatment recommendations for patients with estrogen receptor-positive early stage breast cancer and correlation with estimation of recurrence risk by breast cancer specialists. Oncologist. 2011;16(11):1520-6.

14. Eiermann W, Rezai M, Kummel S, Kuhn T, Warm M, Friedrichs $K$, Schneeweiss A, Markmann S, Eggemann H, Hilfrich J, et al. The 21-gene recurrence score assay impacts adjuvant therapy recommendations for ERpositive, node-negative and node-positive early breast cancer resulting in a risk-adapted change in chemotherapy use. Ann oncol. 2013;24(3):618-24.

15. Carlson JJ, Roth JA. The impact of the Oncotype Dx breast cancer assay in clinical practice: a systematic review and meta-analysis. Breast Cancer Res Treat. 2013:141(1):13-22.

16. Dinan MA, Mi X, Reed SD, Lyman GH, Curtis LH. Association between use of the 21-gene recurrence score assay and receipt of chemotherapy among Medicare beneficiaries with early-stage breast cancer, 2005-2009. JAMA oncology. 2015;1(8):1098-109.

17. Levine MN, Julian JA, Bedard PL, Eisen A, Trudeau ME, Higgins B, Bordeleau $L$, Pritchard Kl. Prospective evaluation of the 21-gene recurrence score assay for breast cancer decision-making in Ontario. J Clin Oncol. J Clin Oncol. 2016;34:1065-71.

18. Mamounas EP, Tang G, Fisher B, Paik S, Shak S, Costantino JP, Watson D, Geyer CE Jr, Wickerham DL, Wolmark N. Association between the 21-gene recurrence score assay and risk of locoregional recurrence in node-negative, estrogen receptor-positive breast cancer: results from NSABP B-14 and NSABP B-20. J Clin Oncol. 2010;28(10):1677-83.

19. Jegadeesh NK, Kim S, Prabhu RS, Oprea GM, Yu DS, Godette KG, Zelnak AB, Mister D, Switchenko JM, Torres MA. The 21-gene recurrence score and locoregional recurrence in breast cancer patients. Ann Surg Oncol. 2015 22(4):1088-94.

20. Solin L, Gray R, Goldstein LJ, Recht A, Baehner FL, Shak S, Badve S, Perez EA, Shulman LN, Martino S, et al. Prognostic value of biologic subtype and the 21-gene recurrence score relative to local recurrence after breast conservation treatment with radiation for early stage breast carcinoma: results from the eastern cooperative oncology group E2197 study. Breast Cancer Res Treat. 2012;134(2):683-92.

21. Turashvili G, Chou JF, Brogi E, Morrow M, Dickler M, Norton L, Hudis C, Wen HY. 21-gene recurrence score and locoregional recurrence in lymph nodenegative, estrogen receptor-positive breast cancer. Breast Cancer Res Treat. 2017;166(1):69-76.

22. Edge S, Byrd DR, Compton CC, Fritz AG, Greene FL, Trotti A, editors. AJCC Cancer Staging Manual, 7th edn. New York, NY: Springer; 2010.

23. Hudis CA, Barlow WE, Costantino JP, Gray RJ, Pritchard KI, Chapman JA, Sparano JA, Hunsberger S, Enos RA, Gelber RD, et al. Proposal for standardized definitions for efficacy end points in adjuvant breast cancer trials: the STEEP system. J Clin Oncol. 2007;25(15):2127-32.

24. Hassett MJ, Silver SM, Hughes ME, Blayney DW, Edge SB, Herman JG, Hudis CA, Marcom PK, Pettinga JE, Share D, et al. Adoption of gene expression profile testing and association with use of chemotherapy among women with breast cancer. J Clin Oncol. 2012;30(18):2218-26.

25. Wen HY, Krystel-Whittemore M, Patil S, Pareja F, Bowser ZL, Dickler MN, Norton L, Morrow M, Hudis CA, Brogi E. Breast carcinoma with an Oncotype Dx recurrence score $<18$ : rate of distant metastases in a large series with clinical follow-up. Cancer. 2017;123(1):131-7.

26. Yamashita H, Ogiya A, Shien T, Horimoto Y, Masuda N, Inao T, Osako T, Takahashi M, Endo Y, Hosoda M, et al. Clinicopathological factors predicting early and late distant recurrence in estrogen receptor-positive, HER2negative breast cancer. Breast Cancer. 2016;23(6):830-43.

27. Sestak I, Cuzick J. Markers for the identification of late breast cancer recurrence. Breast Cancer Res. 2015;17:10.

28. Wapnir IL, Anderson SJ, Mamounas EP, Geyer CE Jr, Jeong JH, Tan-Chiu E, Fisher B, Wolmark N. Prognosis after ipsilateral breast tumor recurrence and locoregional recurrences in five National Surgical Adjuvant Breast and bowel project node-positive adjuvant breast cancer trials. J Clin Oncol. 2006; 24(13):2028-37.

29. Fredholm H, Magnusson $K$, Lindstrom LS, Garmo H, Falt SE, Lindman $H$, Bergh J, Holmberg L, Ponten F, Frisell J, et al. Long-term outcome in young women with breast cancer: a population-based study. Breast Cancer Res Treat. 2016;160(1):131-43.

30. Partridge AH, Hughes ME, Warner ET, Ottesen RA, Wong YN, Edge SB, Theriault RL, Blayney DW, Niland JC, Winer EP, et al. Subtype-dependent relationship between young age at diagnosis and breast cancer survival. J Clin Oncol. 2016:34(27):3308-14.

31. Sparano JA. TAILORx: trial assigning individualized options for treatment (Rx). Clin Breast Cancer. 2006;7(4):347-50.

32. Sparano JA, Gray RJ, Makower DF, Pritchard Kl, Albain KS, Hayes DF, Geyer CE Jr, Dees EC, Perez EA, Olson JA Jr, et al. Prospective validation of a 21gene expression assay in breast cancer. N Engl J Med. 2015;373(21):2005-14.

33. Ramsey SD, Barlow WE, Gonzalez-Angulo AM, Tunis S, Baker L, Crowley J, Deverka P, Veenstra D, Hortobagyi GN. Integrating comparative effectiveness design elements and endpoints into a phase III, randomized clinical trial (SWOG S1007) evaluating oncotypeDX-guided management for women with breast cancer involving lymph nodes. Contemp Clin Trials. 2013;34(1):1-9.

\section{Submit your next manuscript to BioMed Central and we will help you at every step:}

- We accept pre-submission inquiries

- Our selector tool helps you to find the most relevant journal

- We provide round the clock customer support

- Convenient online submission

- Thorough peer review

- Inclusion in PubMed and all major indexing services

- Maximum visibility for your research

Submit your manuscript at www.biomedcentral.com/submit
) Biomed Central 